\title{
Phobia Exposure Therapy Using Virtual and Augmented Reality: A Systematic Review
}

\author{
Ghaida Albakri ${ }^{1}$, Rahma Bouaziz ${ }^{1,2}{ }^{\mathbb{D}}$, Wallaa Alharthi ${ }^{3}$, Slim Kammoun ${ }^{1,4} \mathbb{D}^{\mathbb{D}}$, Mohammed Al-Sarem ${ }^{1,5}$ (D) \\ Faisal Saeed ${ }^{1,6}$ and Mohammed Hadwan ${ }^{7,8, * \mathbb{D}}$
}

Citation: Albakri, G.; Bouaziz, R.; Alharthi, W.; Kammoun, S.; Al-Sarem, M.; Saeed, F.; Hadwan, M. Phobia Exposure Therapy Using Virtual and Augmented Reality: A Systematic Review. Appl. Sci. 2022, 12, 1672. https://doi.org/10.3390/ app12031672

Academic Editors: Manuel Duarte Ortigueira, Carla M. A. Pinto, Arnaldo Guimarães Batista and Jia Chen

Received: 23 November 2021

Accepted: 28 January 2022

Published: 5 February 2022

Publisher's Note: MDPI stays neutral with regard to jurisdictional claims in published maps and institutional affiliations.

Copyright: (C) 2022 by the authors. Licensee MDPI, Basel, Switzerland. This article is an open access article distributed under the terms and conditions of the Creative Commons Attribution (CC BY) license (https:// creativecommons.org/licenses/by/ $4.0 /)$.
1 College of Computer Science and Engineering, Taibah University, Medina 42353, Saudi Arabia; ghaidalbakri01@gmail.com (G.A.); rkammoun@taibahu.edu.sa (R.B.); skammoun@taibahu.edu.sa (S.K.); msarem@taibahu.edu.sa (M.A.-S.); fsaeed@taibahu.edu.sa (F.S.)

2 ReDCAD Laboratory, University of Sfax, Sfax 3029, Tunisia

3 College of Community, Computer Sciences and Informatics, Taibah University, Medina 42353, Saudi Arabia; wharthi@taibahu.edu.sa

4 LaTICE Research Laboratory, University of Tunis, Tunis 1938, Tunisia

5 Department of Computer Science, Saba'a Region University, Mareb, Yemen

6 School of Computing and Digital Technology, Birmingham City University, Birmingham B4 7XG, UK

7 Department of Information Technology, College of Computer, Qassim University, Buraydah 51452, Saudi Arabia

8 Department of Computer Science, College of Applied Sciences, Taiz University, Taiz 6803, Yemen

* Correspondence: m.hadwan@qu.edu.sa

\begin{abstract}
A specific phobia is a common anxiety-related disorder that can be treated efficiently using different therapies including exposure therapy or cognitive therapy. One of the most famous methods to treat a specific phobia is exposure therapy. Exposure therapy involves exposing the target patient to the anxiety source or its context without the intention to cause any danger. One promising track of research lies in VR exposure therapy (VRET) and/or AR exposure therapy (ARET), where gradual exposure to a negative stimulus is used to reduce anxiety. In order to review existing works in this field, a systematic search was completed using the following databases: PubMed, ProQuest, Scopus, Web of Science, and Google Scholar. All studies that present VRET and/or ARET solutions were selected. By reviewing the article, each author then applied the inclusion and exclusion criteria, and 18 articles were selected. This systematic review aims to investigate the previous studies that used either VR and/or AR to treat any type of specific phobia in the last five years. The results demonstrated a positive outcome of virtual reality exposure treatment in the treatment of most phobias. In contrast, some of these treatments did not work for a few specific phobias in which the standard procedures were more effective. Besides, the study will also discuss the best of both technologies to treat a specific phobia. Furthermore, this review will present the limitations and future enhancements in this field.
\end{abstract}

Keywords: augmented reality; virtual reality; specific phobia; exposure therapy

\section{Introduction}

Virtual reality is a technology that is capable of creating scenarios of the real world or any imaginative reality. It can simulate the real world and immerse the users so that they cannot distinguish it from the real world [1]. In addition, virtual reality can develop artificial experiences that allow human-machine interaction that works on all human senses. The presence capability provided by AR and VR lets the user feel they are situated in a specific place can open many potential avenues for psychology. VR experience requires specific hardware called a headset (e.g., Oculus Rift, HTC Vive, and Samsung Gear VR). Virtual reality proves its ability to treat many psychological disorders [2]. The treatment related to two advantages of virtual reality includes the control that makes it safe and the ability to create a world beyond the real world [1]. 
On the other hand, augmented reality is a technology that enriches the real world with digital data. AR allows the integration of virtual objects into the real world by calculating the correct positions of the camera. Beyond this, augmented reality allows digital content including 3D models, videos, images, etc. to overlay real-world objects. Augmented reality applications include many industries such as learning, health, retail, work, and entertainment [3]. However, AR was tested to treat some psychological disorders and found to be similar to VR in the matter of treating phobias [4].

Virtual reality has treated many types of a specific phobia, which is an anxiety-related disorder, over the past five years. Several recent surveys discussed the efficiency of this technology [1]. Furthermore, only one review discussed the ability of both technologies to treat specific phobias efficiently [5], but no reviews of all related AR studies were found during the preparation of this work. This review is designed to systematically examine the available evidence about the efficacy of VR exposure therapy (VRET) and AR exposure therapy (ARET) for phobias, critically describe some of the most important challenges in the field, and discuss possible directions.

In this survey, we aim to investigate the types of a specific phobia treated by virtual reality and augmented reality or by both. In addition, we declare the phobia types that have not been treated using one of the technologies. Furthermore, we examine the potential of using both technologies at the same time to treat one of the phobias more efficiently.

The remained of this paper is organized into four sections: (1) the background discussion of specific phobia, exposure therapy, virtual reality, and augmented reality; (2) the methodology (i.e., review questions, review protocol, source of information, search strategy, inclusion and exclusion, study selection, quality assessment, and related survey); (3) the analysis of the published literature; (4) the discussion (i.e., challenge, future works).

\section{Background}

Under this section, the basic background details of this problem along with the issues and challenges faced by the visually impaired are discussed.

\subsection{Specific Phobia}

According to the International Classification of Diseases proposed by the Word Health Organization (WHO) (https://icd.who.int/en (accessed on 20 October 2021)), anxiety disorder is a subdivision of mental illness. It includes several of the most common disorders: specific phobias, panic disorder, social anxiety disorder, and generalized anxiety disorder [6]. The term "phobia" is defined as the uncontrollable fear of entities or circumstances and is not consistent with the risk presented [7]. A specific phobia is described as an undesirable fear generated by a certain entity or circumstance, such as a fear of animals, flying, heights, etc. However, individuals with one form of specific phobia tend to have more forms instead of only one [7]. The consequences of specific phobias are long durations, leading to serious physical and psychological reactions that cause the patient many difficulties related to their daily social life [7]. Moreover, a phobia is considered as an irrational continuous fear in comparison with the subject danger.

Four known types of specific phobias include (1) animal phobia: fear of different kinds of animals (zoophobia) such as spiders, snakes, or dogs [8]; (2) natural phobia: fear of nature or environment such as heights (acrophobia), thunderstorms (astraphobia), or water (aquaphobia); (3) situational phobia: fear of a situation such as flying [9], driving [10], or closed areas [11], and (4) blood-injection-injury phobia (BII) [12]: fear of blood-related operations (hemophobia) [13] and dental operations [14]. To treat specific phobias, different types of therapy can be used; exposure therapy is considered the most effective [15].

\subsection{Exposure Therapy}

Specific phobia treatment can be done in different ways such as through exposure therapy, cognitive therapy, relaxation techniques and/or short-term pharmacotherapy [16]. Exposure therapy aims to treat the anxiety disorder by exposing the patient gradually to 
the source of fear in a managed and controllable environment that ensures the patient's safety using images, simulation, videos or by presenting the phobia object [17-19] without a direct exposition to the real situation. Exposure takes various forms, including graduated versus intense (or flooding therapy), brief versus prolonged, with and without various cognitive and somatic coping strategies, and imaginal, interceptive, or in vivo (or in real life) [20]. Ref. [16] present a systematic review on virtual reality exposure treatment in phobias, the results demonstrated a positive outcome of virtual reality exposure treatment of most phobia types. However, the treatment efficiency can be measured when the fear decreases or disappears once the patient is placed in the same situation with no fear response. Exposure treatment effectiveness has been proved by many studies to defeat specific phobias such as acrophobia [21], zoophobia, etc. [7].

Much research shows that the types of specific phobia vary in measurements such as age, sex, apprehension focus, time, phobic response predictability, and physiological reaction type [22-24].

Emerging technologies such as augmented reality and virtual reality have proven to be an effective treatment strategy for anxiety disorders [25]. They provided an interesting solution as traditional exposure therapy, and they could be a preferable alternative in many situations, where the user cannot be confronting the desired entity, or the manageability of the feared entity cannot be accomplished.

\subsection{Virtual Reality}

Virtual reality is a technology that helps in anxiety disorder treatment [26]. However, virtual reality aims to immerse the person by taking them to another place while they have not moved physically. Moreover, confounding the human brain requires special equipment and software that are responsible for creating the illusion: mainly, platforms to run the application on desktop and mobile, hardware sensors for motion tracking, input devices for motion recognition, and head-mounted displays or stereoscopic displays (HMDs) to display the virtual environment [14,27]. A virtual reality experience consists of four elements including virtual world, immersion, sensory feedback, and interactivity.

The virtual world element describes the given medium content. The virtual world's existence can be in a different form, the originator's mind, computer software, or on paper reality [28]. However, a virtual world based on computer software is an object's representation inside the simulation. By viewing the virtual world using software that fetches objects and interacts with them by physical immersion, the user will experience the true meaning of virtual reality [16].

The immersion element implies the process of overwhelming the user in an alternate reality [28]. Mental immersion and physical immersion are the two ways in which the term "immersion" can be used. The state of deeply engaging the user intellectually is the definition of mental immersion. On the other hand, physical immersion is defined as using technology to stimulate the body's senses artificially. Physical immersion is referred to as the VR system property that substitutes or enhances the stimulus participant's senses.

Sensory feedback is a fundamental element in virtual reality. In VR systems based on the physical position of the participants, sensory feedback is provided. A high-speed computer is required to accomplish instant interactive feedback. The participant's movement must be tracked by the VR system to base the sensory output on the correct participant position. Position tracking can be defined as an object's computerized position or location sensing in the physical world. Usually, the participant's head and hand are tracked by the VR system. However, body joints can also be tracked in advanced VR systems. To accomplish tracking in VR systems, various technologies can be employed and input devices such as a head-tracking system or a joystick.

Interactivity elements provide authenticity for virtual reality, where the user finds themselves responding to their actions. Therefore, interactivity is an important element of virtual reality. Moreover, interactivity is concerned with two forms: one affects the world within the computer software, the other persuades the user of that change. Changing object 
location and moving around in the virtual world are both interactivity examples the user can usually perform.

Researchers in [6] reviewed several recent works. They described that VRET implementation for a specific phobia usually applies the same treatment protocols used in traditional treatments of a phobia. These include an explanation of the treatment nature for the patient before the start that the phobic level of the patient must be determined in advance by information-gathering procedures and that the gathered information will be a base for establishing stimulus hierarchy levels.

\subsection{Augmented Reality}

Augmented reality is defined as adding digital information generated by the computer to the real world to enhance and enrich it while viewing a real-time physical real-world environment [3]. The method of combining real-time with digital information helps the user to interact with both worlds at the same time [29]. Three main characteristics of the AR system can be defined: (1) real and virtual combining, (2) real-time interactivity, and (3) three-dimensional (3D) registration. Registration means aligning virtual objects seamlessly into 3D space in the real world, which affects the whole process if it is not accurate [3].

Augmented reality (AR) incorporates virtual components into the real environment. This can be effective for exposure therapy with specific phobias. AR exposure therapy (ARET) is a sort of exposure treatment that allows clients to interact with a virtual representation of an object or scenario in the real world in order to lessen fear or avoidance. In contrast to VR exposure treatment (VRET), the client is not immersed in a whole virtual environment using a head-mounted display (HMD), but rather a virtual object (e.g., a spider) is added to the current surroundings. Clients can utilize HMDs in ARET, but the technology also allows them to use projection displays or commonplace portable devices like smartphones and tablets. AR can use markers (stylized real items on which the software overlays a virtual element) or a markerless technique, in which the content is arranged relative to the environment, GPS position, and compass of the device, to successfully see an object in the real world. The absence of markers in AR could lead to a greater sensation of presence and anxiety of the virtual aspect.

Augmented reality exposure therapy has been used to treat specific phobias of small animals (spiders and cockroaches) in multiple studies which prove its capability of exposure therapy treatment. VRET and ARET approaches have been proved to improve most patients ${ }^{\prime}$ phobia levels. VRET is used for multiple types of anxiety disorder in comparison to ARET. ARET provides a better experience since it adds digital information to the real world instead of generating a whole new virtual one. Moreover, realism can be achieved better by ARET than VRET.

\subsection{Cybersickness in VRET and ARET}

Cybersickness is a type of motion sickness caused by immersive within virtual reality and augmented reality applications. Between 20 and $95 \%$ of users will have some sort of cybersickness, ranging from a mild headache to an emetic response, depending on the immersive content [30]. Physiological symptoms of anxiety and cybersickness overlap and may confound both scientific research and clinical practice.

\section{Contribution}

Emerging technologies such as augmented reality and virtual reality have proven to be an effective treatment strategy for anxiety disorders, and they could be a preferable alternative in many situations, where the user cannot be confronting the desired entity, or the manageability of the feared entity cannot be accomplished.

However, VR could be used as a first step or the first session in exposure therapy for a different type of phobia with a different level of fear. It will encourage the patient to interact with the fear while keeping in mind that it is all a digital safe environment. After that, another session of AR could be used to treat the phobia more precisely using heart 
rate sensors and hand tracking. AR could be used for other types of phobias since there are only a limited number of studies associated with it, such as with small animal phobias. The current research focuses on using one of the two technologies, AR, and VR, mostly VR where it shows a capability to treat different types of phobias. In this paper, we will focus on using VR and AR to treat one type of specific phobia.

\section{Review Methodology}

\subsection{Review Questions}

This review was conducted to answer the following questions:

- Q1: What are the specific phobias treated by virtual reality exposure therapy in the last five years?

- $\quad$ Q2: What are the specific phobias treated by augmented reality exposure therapy in the last five years?

- Q3: How can virtual reality and augmented reality help in exposure therapy treatment?

\subsection{Related Survey}

The latest research has systematically reviewed exposure therapy using augmented reality or virtual reality in treating anxiety-related disorders. Ref. [5] present a rapid review conducted included the last five years of studies that treat specific phobia including the psychotherapy, technology-assisted therapy, and pharmacotherapy. The result included augmented reality and virtual reality under technology-assisted therapy. Virtual reality exposure therapy dominates in the last five years while augmented reality has not been used to treat phobia lately. In another review work, ref. [31] aimed to answer the question of how to perform exposure therapy in a virtual reality environment so that it is effective. After an analysis of 49 research papers on specific phobias, the authors conclude that VRET can be an effective way to treat anxiety disorder by increasing the frequency of sessions and adding drug therapy. These results were also confirmed by [16].

The researchers in [6] aimed to review all the VRET-related papers in order to evaluate all the studies achieved within the field in the form of a systematic review. However, evaluating all the past research led to finding gaps and exploring a new methodology. Ref. [1] included all the evidence that proves the VRET efficiency in treating anxiety-related disease within the past five years. Moreover, while highlighting the achievements, the limitations were also included. Ref. [22] provided an overview of all the existing studies that discuss treatment of a specific phobia using virtual reality, while focusing on the advantages and effectiveness of virtual reality [22]. However, the shortage in using augmented reality for treating a specific phobia opens the door for many future studies, while only one paper discussed its uses recently [5]. Table 1 shows the existing review papers of anxiety-related disorder exposure therapy.

\subsection{Review Protocol}

The research protocol will be based on the following steps: (1) a specific phase will be used in several databases including Scopus, PubMed, ProQuest, and Google Scholar,

(2) title screening will determine the included records followed by abstract screening,

(3) full-text scanning will be used to choose the correct records that follow the research criteria, (4) the selected literature will be analyzed to extract the results, and (5) the literature review will be interoperated while discussing the limitations and opportunities.

According to [23], each primary study included in the systematic review must be assigned a quality value. The quality value will be determined based on the following five quality assessment questions (QAs):

1. QA1: Is the solution proposed using either augmented reality or virtual reality to treat the specific phobia?

2. QA2: Is the research methodology defined in the article clearly?

3. QA3: Is evaluation defined in the article clearly?

4. QA4: Is the proposed solution tested on specific phobia patients aged over 18 ? 
5. QA5: Does the evaluation include a follow-up?

Table 1. Existing review papers on anxiety disorder exposure therapy.

\begin{tabular}{|c|c|c|c|c|c|c|}
\hline Title & Paper & Review Type & \# of Studies & VR & AR & Area of Interest \\
\hline $\begin{array}{l}\text { Recent developments in the } \\
\text { intervention of specific phobia } \\
\text { among adults: A rapid review }\end{array}$ & [5] & $\begin{array}{l}\text { Rapid } \\
\text { Review }\end{array}$ & 33 & $\checkmark$ & $\checkmark$ & $\begin{array}{ll}\text { 1. } & \text { Psychotherapy } \\
\text { 2. Technology-assisted } \\
\text { therapy } \\
\text { 3. Pharmacotherapy }\end{array}$ \\
\hline $\begin{array}{l}\text { Implementations of Virtual } \\
\text { Reality for Anxiety-Related } \\
\text { Disorders: Systematic Review }\end{array}$ & [6] & $\begin{array}{l}\text { Systematic } \\
\text { Review }\end{array}$ & 49 & $\checkmark$ & & $\begin{array}{ll}\text { 1. } & \text { Specific Phobias } \\
\text { 2. } & \text { Post-Traumatic Stress } \\
& \text { Disorder and Acute } \\
\text { 3. Anxiety } \\
\text { 4. } \\
\begin{array}{l}\text { Paranoia or Paranoid } \\
\text { Ideations }\end{array}\end{array}$ \\
\hline $\begin{array}{l}\text { Recent Progress in Virtual } \\
\text { Reality Exposure Therapy for } \\
\text { Phobias: A Systematic Review }\end{array}$ & [1] & $\begin{array}{c}\text { Systematic } \\
\text { Review }\end{array}$ & 11 & $\checkmark$ & & $\begin{array}{ll}\text { 1. } & \text { Specific Phobia for Small } \\
\text { Animals } \\
\text { 2. Agoraphobia } \\
\text { 3. Flying phobia }\end{array}$ \\
\hline $\begin{array}{l}\text { Virtual Reality-Enhanced } \\
\text { Extinction of Phobias and } \\
\text { Post-Traumatic Stress }\end{array}$ & [22] & $\begin{array}{c}\text { Literature } \\
\text { Review }\end{array}$ & 43 & $\checkmark$ & & $\begin{array}{ll}\text { 1. } & \text { Specific Phobias } \\
\text { 2. } & \text { Post-Traumatic stress } \\
\text { disorder }\end{array}$ \\
\hline $\begin{array}{l}\text { Virtual Reality Exposure } \\
\text { Treatment in Phobias: A } \\
\text { Systematic Review }\end{array}$ & [16] & $\begin{array}{l}\text { Systematic } \\
\text { Review }\end{array}$ & 30 & $\checkmark$ & & $\begin{array}{l}\text { 1. Specific Phobias } \\
\text { 2. Exposure therapy towards } \\
\text { Phobia Rehabilitation }\end{array}$ \\
\hline $\begin{array}{l}\text { Tips for Effective } \\
\text { Implementation of Virtual } \\
\text { Reality Exposure Therapy in } \\
\text { Phobias-A Systematic Review }\end{array}$ & [31] & $\begin{array}{c}\text { Systematic } \\
\text { Review }\end{array}$ & 49 & $\checkmark$ & & $\begin{array}{ll}\text { 1. } & \text { Specific Phobias } \\
\text { 2. } & \text { Agoraphobia } \\
\text { 3. } & \text { Social Phobia }\end{array}$ \\
\hline
\end{tabular}

Table 2 presents our findings regarding specific phobia using augmented and virtual reality, and Table 3 provides existing paper types.

Table 2. Existing papers on specific phobia exposure therapy using virtual and augmented reality.

\begin{tabular}{ccccccc}
\hline Paper & QA1 & QA2 & QA3 & QA4 & QA5 & Total \\
\hline$[24]$ & 1 & 1 & 0 & 1 & 0 & 3 \\
{$[32]$} & 1 & 1 & 1 & 1 & 0 & 4 \\
{$[33]$} & 1 & 1 & 1 & 1 & 1 & 5 \\
{$[34]$} & 1 & 1 & 1 & 1 & 0 & 4 \\
{$[35]$} & 1 & 1 & 1 & 1 & 0 & 4 \\
{$[36]$} & 1 & 1 & 0 & 1 & 0 & 3 \\
{$[14]$} & 1 & 1 & 1 & 1 & 1 & 5 \\
{$[37]$} & 1 & 1 & 1 & 1 & 1 & 5 \\
{$[38]$} & 1 & 1 & 1 & 1 & 1 & 5 \\
{$[39]$} & 1 & 1 & 1 & 1 & 1 & 5 \\
{$[40]$} & 1 & 1 & 1 & 1 & 1 & 5 \\
{$[41]$} & 1 & 1 & 1 & 1 & 1 & 5 \\
{$[42]$} & 1 & 1 & 1 & 1 & 0 & 4 \\
{$[21]$} & 1 & 1 & 0 & 1 & 1 & 4 \\
{$[43]$} & 1 & 1 & 1 & 1 & 0 & 4 \\
{$[44]$} & 1 & 1 & 1 & 1 & 1 & 5 \\
{$[45]$} & 1 & 1 & 1 & 1 & 1 & 5 \\
\hline
\end{tabular}


Table 3. Type of papers.

\begin{tabular}{ccc}
\hline Paper & Phobia & Type \\
\hline$[24]$ & Snake Phobia & Trial \\
{$[32]$} & Height Phobia & Trial \\
{$[33]$} & Shark Phobia & Case study \\
{$[34]$} & Height Phobia & Trial \\
{$[35]$} & Cockroach Phobia & Case study \\
{$[36]$} & Spider Phobia & Trial \\
{$[14]$} & Dental Phobia & Case study \\
{$[37]$} & Height Phobia & Pilot study \\
{$[38]$} & Dental Phobia & Spider Phobia \\
{$[39]$} & Randomized controlled trial \\
{$[40]$} & Blood-Injection-Injury (BII) Phobia & Randomized controlled trial \\
{$[41]$} & Spider and Cockroach Phobia & Randomized controlled trial \\
{$[42]$} & Driving Phobia & Randomized controlled trial \\
{$[21]$} & Height Phobia & Randomized controlled trial \\
{$[43]$} & Spider Phobia & Randomized controlled trial \\
{$[46]$} & Height Phobia & Case Study \\
{$[44]$} & Height Phobia & Randomized controlled trial \\
{$[45]$} & Flight Phobia & Randomized controlled trial \\
\hline
\end{tabular}

\subsection{Source of Information and Search Strategy}

A comprehensive search was conducted in PubMed, ProQuest, Scopus, Web of Science, and Google Scholar of the past five years involves articles, books, reports, and magazines. All the studies must be written in English and published between 1 January 2016 and 1 November 2020.

The phase searching method used is as follows: ("Specific phobia" OR "Phobia") AND ("Augmented reality" OR "Virtual reality") AND ("Exposure therapy" OR "Treatment"), with an English-language filter and publication date between January 2016 and November 2020. An initial 5328 records were collected from the three databases and Google Scholar to conduct this research. Existing research in the selected databases using the search strategy is listed in Table 4. There were a total of 71 records retrieved from PubMed, 1095 from ProQuest, 202 from Scopus, and 3960 from Google Scholar. The online databases used in the search strategy were:

- PubMed,

- ProQuest,

- Scopus,

- Web of Science,

- Google Scholar.

Table 4. Existing research in the selected databases using the search strategy.

\begin{tabular}{|c|c|c|c|}
\hline Database & Retrieved Records & Phase & Filters \\
\hline PubMed & 71 & ("Specific Phobia" OR & \\
\hline ProQuest & 1095 & "Phobia") AND ("augmented & Publication date: \\
\hline Scopus & 202 & reality" OR “Virtual reality") & from january 2016 \\
\hline Web of Science & 153 & AND ("Exposure Therapy" & to Novemb \\
\hline Google Scholar & 3960 & OR “Treatment”) & English language \\
\hline Total & & 5481 & \\
\hline
\end{tabular}

\subsection{Inclusion and Exclusion Criteria}

The obtained records from the five databases, PubMed, ProQuest, Scopus, Web of Science, and Google Scholar, using the selected phrases results in a total of 5481. The remaining records after scanning the title resulted in 277. The eliminated records not related to treating phobia using either ARET or VRET were 5204. Duplication removal 
resulted in 109 records, eliminating 168 duplicated records. Abstract scanning produced 60 records, with 49 records eliminated not proposing an ARET or VRET treatment for a specific phobia. Full-text scanning yielded 18 to be reviewed in this paper, while 42 were excluded. A flow diagram of included reviews and the selection process is presented in Figure 1.

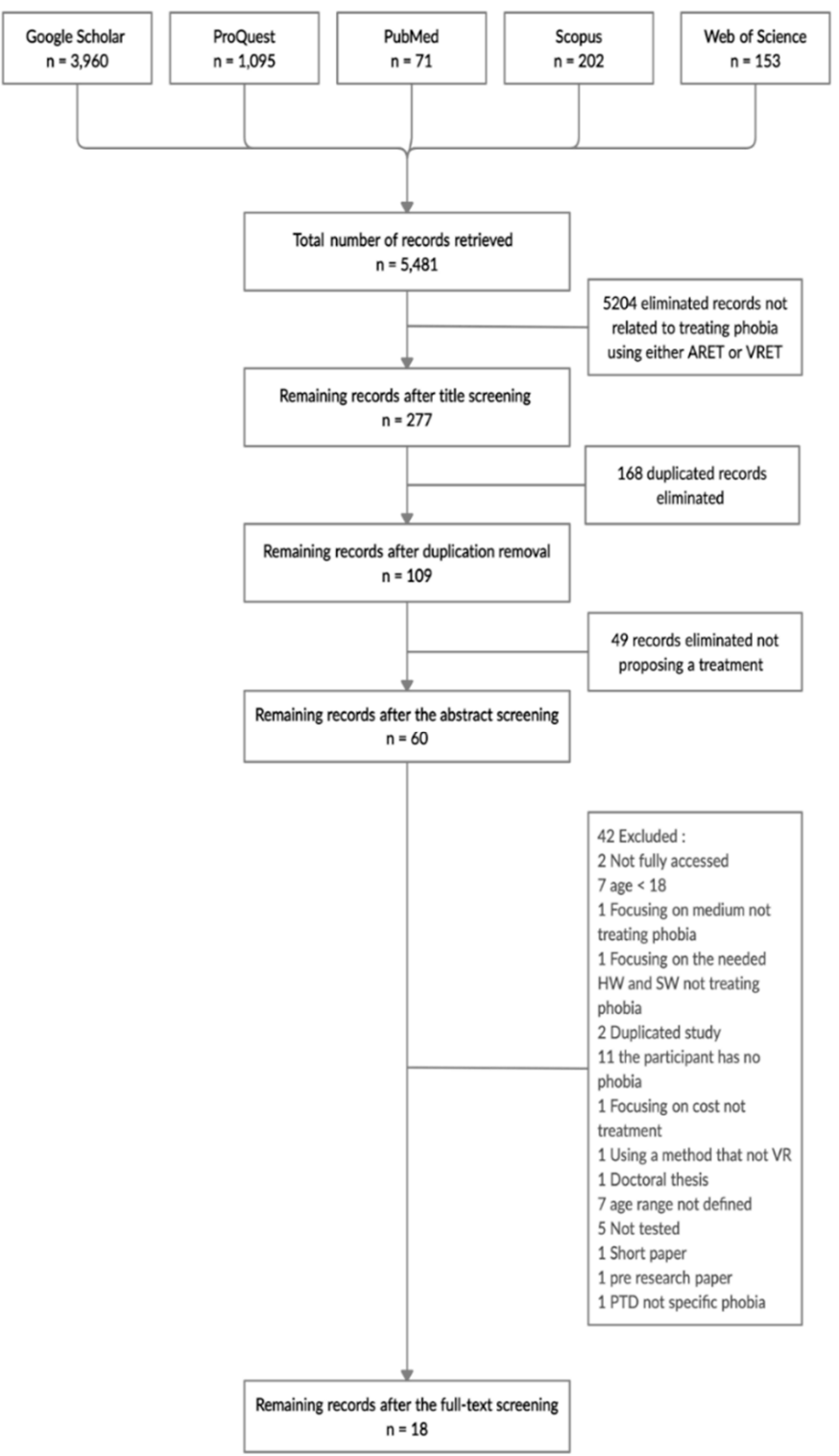

Figure 1. Systematic review search PRISMA.

\subsection{Study Selection}

Studies included in this review must follow the following criteria: (1) published between the year 2016 and 2020, (2) must provide a solution for treating the specific phobia by virtual reality, augmented reality exposure therapy, or both, (3) participants aged 18 or over and must be diagnosed with a specific phobia, (4) not based on pharmacological agents, (5) not combined with any other therapy-only exposure therapy, and (6) published in English language only. Figure 2 shows filtering of the paper based on the title, then abstract, and finally the full text. Figure 3 shows the years of the selected papers. 


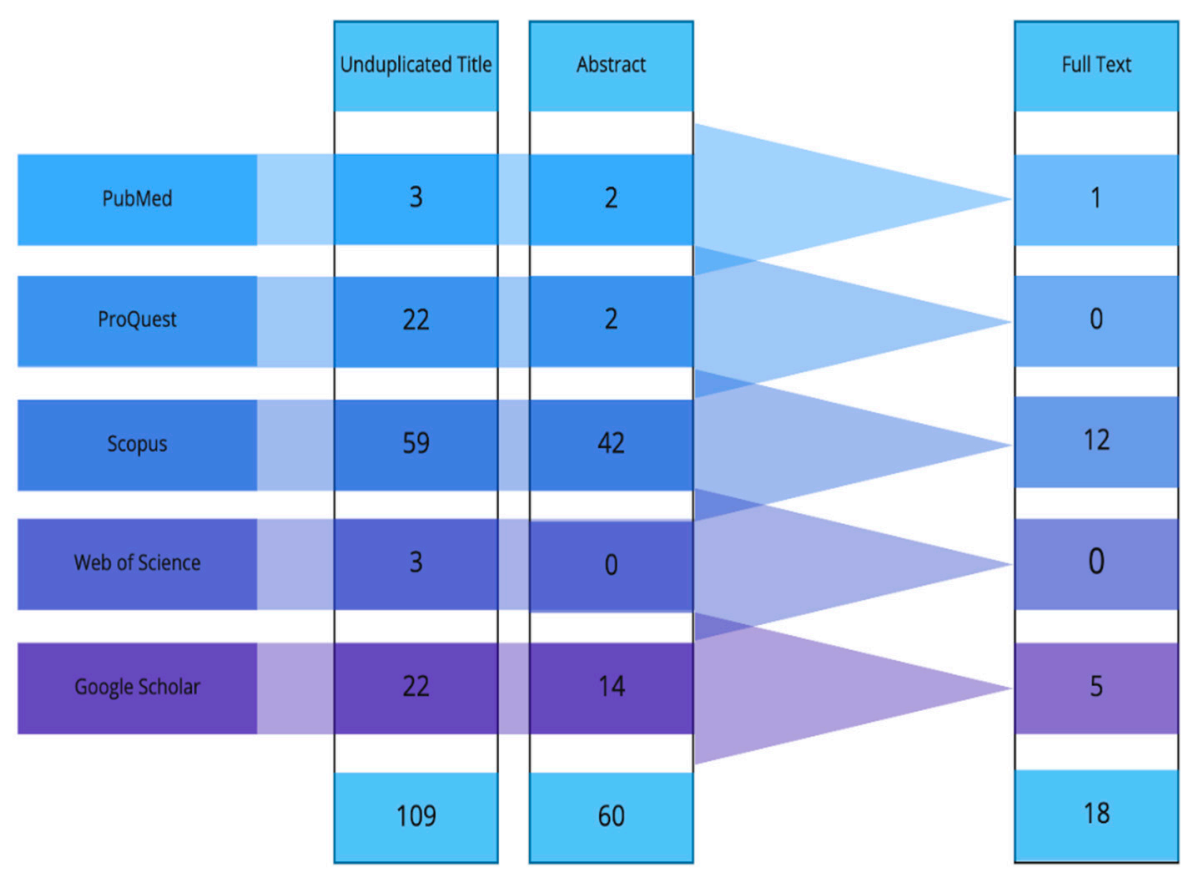

Figure 2. Filtering studies based on the title, abstract, and full text.

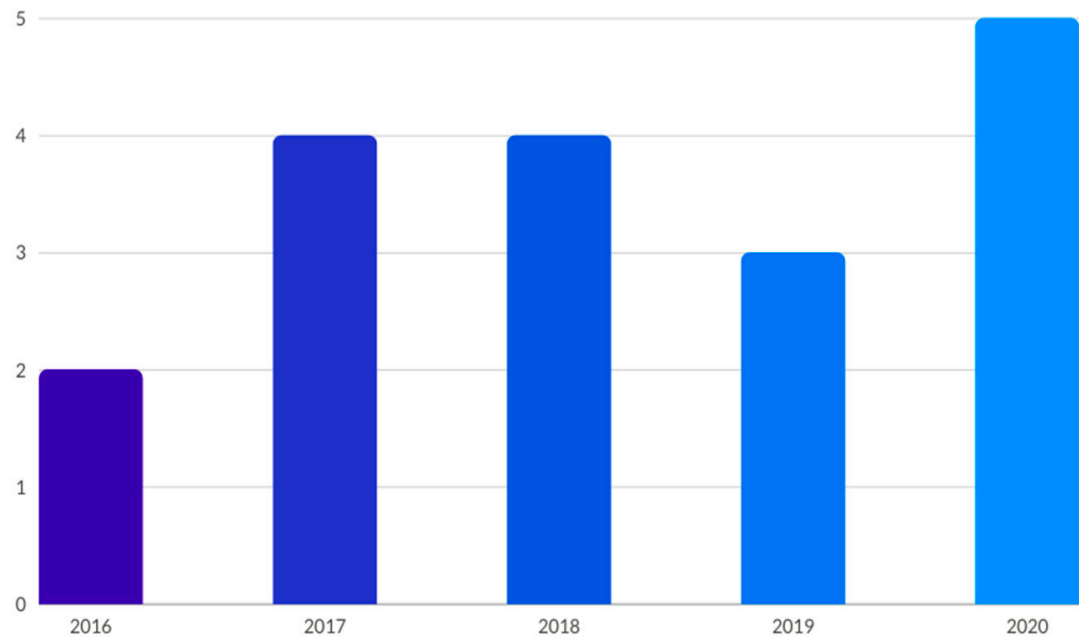

Figure 3. Studies' publication years.

\section{Review of Considered Study}

\subsection{Animal-Specific Phobia}

This section will describe the most popular work found in the literature about animalspecific phobia treatments.

\subsubsection{Spider and Cockroach Phobia}

Cockroach phobia can be implemented easily using either augmented reality or virtual reality. The researchers developed a case study that uses augmented reality object detection, where the presence of a certain object will generate the 3D cockroaches. The application runs on a desktop with an external camera. Furthermore, it contains four different scenarios displayed to the patient including single static cockroaches, single dynamic cockroaches, multiple static cockroaches, and multiple dynamic cockroaches. An evaluation is done on eight cockroach phobia patients, with ages ranging between 20 and 23 years old. Moreover, the evaluation must be preceded by the Fear of Spiders Questionnaire (FSQ) [47] to determine the anxiety level of patients. During the evaluation, the Subjective Units of Discomfort 
Scale (SUD) is used to determine the anxiety level. Moreover, after the application testing, the patients must fill in a Slater-Usoh-Steed Questionnaire (SUS) that measures the realism of the application [35].

A marker-based augmented reality exposure therapy has been developed aiming to treat spider phobia (arachnophobia). Increasing interactivity and decreasing arachnophobia are the main goals of the developed study. The Android application is based on four treatment stages related to the patient's spider fear level, ranging between high intermediate, diffuse, normal, and null. Each patient score in the Fear of Spider Questionnaire (FSQ) will determine the appropriate one of the four stages. Stage one includes a static spider, while stage two contains a moving spider. Moreover, stage three contains multiple static spiders, while multiple moving spiders are included in stage four. An evaluation is conducted from the beginning to determine the patient's fear level and the appropriate treatment stage using the FSQ. However, the evaluation was done on 16 arachnophobia patients with an age range between 18 and 20 years old. A daily session was carried out for one month followed by the same questionnaire to acknowledge the difference with different session times based on the patient responses [36].

A study conducted by [39] aims to compare the performance of virtual reality exposure therapy with the standard in vivo one-session treatment. However, the study relies on a single-session non-inferiority randomized trial. The evaluation was done on a total of 100 spider phobia participants randomized to either virtual reality exposure therapy or in vivo one-session treatment. A Behavioral Avoidance Test (BAT) was used pre-assessment and post-assessment and in the follow-up. For the in vivo one-session treatment, the participants were exposed to three spiders with different sizes gradually for three hours maximum, while rating their anxiety level using a Subjective Unit of Distress (SUD). Virtual reality exposure therapy was conducted using an app developed for the treatment called VIMSE. The app consists of eight levels with a spider that becomes more realistic, and it allows the user to pause the treatment while they also rate anxiety using a SUD [39].

A study has been developed aiming to treat both spider and cockroach phobias using augmented reality instead of the accepted treatment of virtual reality exposure therapy. Thus, a comparison between in vivo exposure therapy and augmented reality exposure therapy is needed to evaluate their acceptance and usefulness. The trial was randomized, controlled, and done using one-session guidelines. The evaluation achieved a total of 63 participants, with 31 patients assigned to the in vivo exposure therapy and 32 patients randomly assigned to the augmented reality therapy. However, the study used several measurements including the BAT, FSQ, Spider Phobia Beliefs Questionnaire (SBQ), Fear and Avoidance Scales, and the Clinician Severity Scale (CSS) on the pre-treatment, post-treatment, and follow-up stages. The session lasted for 180 min maximum while the participants were exposed to 3D cockroaches or spiders in the augmented reality therapy [41].

A study by [43] used a different approach than the rest of the studies. Therefore, $360^{\circ}$ immersive stereoscopic videos were captured using a stereoscopic 3D dual camera that aims to decrease spider phobia. However, 77 spider phobia participants were exposed to the videos of spiders and facts about them. The participants were randomized to either a virtual reality exposure therapy with $360^{\circ}$ immersive videos that last five minutes for each video six times using an Oculus Rift virtual reality headset, or a group controlled by psychoeducation only that watch the documentary for $30 \mathrm{~min}$. Moreover, the virtual reality exposure therapy videos increase the intensity with time where the spider moves closer or moves towards the camera. The evaluation was achieved using several measurements including the FSQ, the BAT, the subjective measures, and the 3D vision questionnaire for pre-treatment and post-treatment [43].

\subsubsection{Shark Phobia (Squalophobia)}

Shark phobia is one of the more difficult phobias to be treated using normal exposure therapy. The greatest feature of virtual reality is considered to be its ability to immerse the 
users in the realistic 3D world. Treating squalophobia using virtual reality counts as the correct choice when dealing with large creatures. Squalophobia treatment through virtual reality exposure therapy was tested in one case study only.

A gradual three-stage system was built to be navigated by the patient freely in the form of walking or swimming as in the real world. The stages are initially started with a pool, followed by a lake, and finally the sea. The system encountered three different interaction levels while including the related audio. Light interaction includes the reaction between the land and water. Average interaction includes the ability to hold scene-related $3 \mathrm{D}$ objects such as stones and sticks. Complex interaction is related to shark behaviour and movement underwater. The system was displayed to the patients using the VR Sony HMD.

An evaluation took place using several anxiety and virtual reality questioners with one thirty-year-old squalophobia patient. However, the evaluation duration was ten sessions long. A follow-up was done twelve months later using the same questioners in the evaluation phase [33].

\subsubsection{Snake Phobia (Ophiophobia)}

One study investigated treating snake phobia using virtual reality exposure therapy in the form of a serious game. The system is divided into two levels, the forest and the cave, and the patient must move around to collect coins and kill the encountered snakes along the way. Level 1 consists of a 3D forest containing several snakes with a lower level of challenge and fear. Level 2 is considered to be the challenging level where the patient emerges in a 3D cave and must defeat a higher number of snakes.

A game evaluation was achieved on ten snake phobia patients aged between 19 and 32. Two evaluation questionnaires used included the snake's phobia assessment and the game's usability [24].

\subsection{Natural Environment-Specific Phobia-Height Phobia (Acrophobia)}

Patient interactivity during the virtual reality exposure therapy was enhanced using a Kinect. Kinect has a built-in motion and movement capturing feature presented by Microsoft. Acrophobia Simulator is a game-based virtual reality exposure therapy that runs on an Android smartphone inside a Google Cardboard and a Kinect. The stages include a river, a city and a mountain, respectively. The patient will lose once they fall at any stage. The difficulty is increased at each stage; the river is the easiest stage, while the mountain is the most difficult one. The evaluation was done using an anxiety questionnaire on ten patients with ages ranging between 21 and 25 years [32].

Another study conducted to treat acrophobia and test the treatment effectiveness of virtual reality consists of two realistic levels. Level 1 displays a 3D mountain view, while level 2 contains a 3D city view. The application was integrated into a VR Gear HMD with a Samsung Galaxy S7 smartphone. The patient's movement was detected using a Kinect sensor. A system evaluation was done on a sample size of twenty patients with ages ranging between 20 and 21 years old. Moreover, the selected sample was divided into two groups having the same or a similar anxiety level; one was exposed to the normal exposure therapy, while the other was exposed to the virtual reality exposure therapy. Over two months, eight sessions were conducted. One session per week was each $25 \mathrm{~min}$ long. A Body Sensation Interpretation Questionnaire (BSIQ) was used to clarify the anxiety symptoms during the test [34].

Another study was conducted to determine the visibility of remote virtual exposure therapy in comparison to traditional virtual reality exposure therapy. Nevertheless, the study was tested on the same sample but divided into groups to compare. The first group received three virtual exposure therapy sessions remotely, while the second received three virtual reality exposure therapy sessions in the presence of a therapist. An evaluation was conducted on a total of six height phobia patients with ages ranging between 18 and 65 years. The testing duration was three weeks, with a total of six sessions, two in a week. Sony HMZ-T1 HMD is used to display the therapy, with a microphone to 
allow communication between the patient and the therapist and a webcam to monitor the patient's activity. The patient was exposed to two different virtual worlds, a subway station and a 24-storey tower block. Pre-exposure, the patient must fill in the State-Trait Anxiety Inventory (STAI form Y-A) and rate their anxiety level on a visual analogue scale (VAS). Post-exposure, the patient must fill in anxiety-related questionnaires using a VAS [37].

OPhobia is a self-guided mobile game developed to deliver virtual reality exposure therapy easily to every height phobia patient using a VR cardboard. An evaluation was achieved on 180 height patients in total that were randomly assigned to either OPhobia or waitlist. The number of measurements used included an acrophobia questionnaire, the Attitudes Towards Heights Questionnaire (ATHQ), Beck Anxiety Inventory (BAI), System Usability Scale (SUS), Igroup Presence Questionnaire (IPQ), Pearlin Mastery Scale, and a Patient Health Questionnaire. However, the app contains six modules each which can be completed in 5 to $20 \mathrm{~min}$. In addition to a virtual therapist that guides the user, the user needs to complete a set of assignments in all the modules. Each assignment aims to expose the user to a different level of height. It also includes four $360^{\circ}$ videos, including the user standing on top of a high building, crossing a bridge, dangling their legs on a rooftop, or standing on a high crane. In the end, the user gets performance feedback to proceed to the next stage [21].

With the enhancement of virtual reality devices, the user can experience stronger emotions that provide the most realistic experience. A study by [46] to analyze the user's feelings found that while using two different virtual reality exposure therapy, the setup hardware will affect the present sensation. An evaluation of the study was achieved on a total of 20 participants with height phobia. Moreover, the study compared two situations: the use of a hand controller and motion recognition cameras of the full body. The system ran on an Oculus Rift VR headset, while the session starts with the user finding themselves on a high floor inside an apartment room. They must accomplish several tasks including getting out of the balcony's open door, then when on the balcony they must hold the railing for minutes and finally get the hanging object in front of them. The user must try the system twice: once while holding the hand controller and once while standing in the area of motion recognition cameras. Then, a comparison of both results must be achieved [46].

In another study conducted by [44], the study was run without the need for therapist supervision. Therefore, a virtual coach was used to guide the user during the virtual reality exposure therapy. However, all the participants were height phobia patients older than 18 years and randomized to either the virtual reality exposure therapy or the usual controlled trial. The virtual exposure therapy consists of six sessions, $30 \mathrm{~min}$ for each session over two weeks and a follow-up conducted after four weeks. The session runs on an HTC Vive VR head-mounted display, where it starts with the patient's ability to walk through the virtual world, which is in a building consisting of ten floors. The coach guides the user through the process and provides them with the full description of each task. Moreover, the user can choose one of the first five floors to achieve certain activities, but each floor has a certain activity, ranging from easier tasks to harder ones. The evaluation measurements include a Heights Interpretation Questionnaire (HIQ), the acrophobia questionnaire (AQ) and the Improving Access to Psychological Therapies (IAPT), and phobia scale avoidance [44].

\subsection{Situation-Specific Phobias}

These involve a fear of specific situations, such as flying, riding in a car or on public transportation, driving, going over bridges or in tunnels, or being in a closed-in place, like an elevator. This section will detail the more important situation-specific phobias.

\subsubsection{Driving Phobia}

A study was developed aiming to treat driving phobia using virtual reality exposure therapy. Thus, the patients were exposed to five sessions in a driving simulator with 14 total participants. The evaluation measures used are a SUD, BAT, an accident-Fear 
Questionnaire (AFQ), Post-traumatic Stress Scale Self-Report (PSS-SR), Beck Depression Inventory II (BDI-II), and a Beck Anxiety Inventory (BAI). The participants were exposed to five $300^{\circ}$ images in every session. Each session contains four scenarios starting with the lowest fear level [42].

\subsubsection{Flight Phobia}

A study was conducted aiming to enhance the existing virtual reality exposure therapy for flight phobia (aerophobia) by using diaphragmatic breathing as a coping mechanism. The study intended to solve the debate that states using a relaxation method might enhance or affect results badly. However, the study was a randomized controlled trial where 29 flight phobia participants were to virtual reality exposure therapy with diaphragmatic breathing, either with six cycles for each minute or without any relaxation technique. The evaluation included collecting the patient biofeedback, which includes heart rate and skin conductance levels [45].

\subsection{Medical Treatment Phobia}

\subsubsection{Blood-Injury-Injection Phobia}

Patients who were diagnosed with a blood-injection-injury (BII) phobia (trypanophobia, hemophobia) [48] were usually treated within in vivo treatment. Only one study by [40], has been conducted to evaluate the effectiveness of virtual reality exposure therapy on this type of phobia and to overcome it in vivo exposure therapy limitations. The randomized controlled trial was conducted on blood-injection-injury phobia patients who were randomly assigned to a waiting list control (WLC) group or virtual reality exposure therapy. Later on, the results of both were compared to determine the phobia reduction and the patient's acceptance. The trial consists of two sessions; the session of virtual reality exposure therapy lasted for $90 \mathrm{~min}$, while the waiting list group lasted for $30 \mathrm{~min}$. The virtual reality exposure therapy session started by asking the patient to arrange three environments with low anxiety including the clinic, dental office and pathology office that are then displayed to the user based on their arrangement using a VR headset. Next, the patient is exposed to two real-life situations with $360^{\circ}$ videos including a nurse that gives an injection and takes a sample of the patient's blood. The evaluation was done using SUDs to collect the user anxiety level. The study continued to have a three-month follow-up stage [40].

\subsubsection{Dental Phobia}

Virtual reality exposure therapy was implemented to treat dental phobia (dentophobia) using an Oculus head-mounted display (HMD). The researchers were also able to see and monitor what patients experience during the therapy through a computer monitor. The session starts by asking the patient to sit in the dental chair and wear the HMD. The scene builds by containing all the dental clinic elements in 3D. Moreover, the patient was exposed to five scenarios including seating with no dental tools, mouth mirror and oral cavity, injection, using the muted drill, and using a drill with sound. Each scenario was repeated many times until the therapist noticed the progress, before moving to the next scenario. The evaluation was conducted on two dental phobia patients aged between 24 and 56 years. The baseline level of anxiety was determined using a VAS. Furthermore, the dental anxiety level was determined using a dental fear survey (DFS) and a modified dental anxiety scale (MDAS). At the end of the exposure, the progress of exposure therapy was measured using a SUD [14].

Another study was conducted by [38] to show the effectiveness of using virtual reality exposure therapy to treat a dental phobia, in addition to highlighting the limitations of other previous studies. A single-blind trial of 30 dental phobia patients was randomized to either an informational pamphlet (IP) condition or virtual reality exposure therapy. However, there were two outcomes of this study: the primary outcomes and the secondary outcomes. The primary outcomes compute and compare the anxiety scores before the intervention and 
the follow-up. The secondary outcomes find the difference between the VRET and the IP condition, behavioural avoidance, heart rate variation, temporal variation, and acceptance of dental treatment. However, several hypotheses were tested to determine the VRET's effectiveness. The evaluation of VRET was done using an Oculus development kit 2 HMD (head-mounted display), which displays five scenarios in one session on the dental chair, while using dental odours to enhance the immersion. The five scenarios are the same as the one used earlier in [14], and the patient must be exposed to the five in the same session. On the other hand, the IP condition was asking the patient to sit in the dental chair for $45 \mathrm{~min}$ while hearing guidelines about overcoming the dental fear [38]. Table 5 summarizes how specific phobia was approached in each paper using augmented reality and virtual.

Table 5. Existing augmented reality and virtual reality exposure therapy for specific phobia treatment.

\begin{tabular}{|c|c|c|c|c|c|c|}
\hline Paper & Phobia Type & $\begin{array}{c}\text { Treatment Condition and } \\
\text { Sample Size }\end{array}$ & Age Range & Solution & Session Number & $\begin{array}{l}\text { Session } \\
\text { Length }\end{array}$ \\
\hline [24] & Snake Phobia & $\operatorname{VRET}(n=9)$ & $19-32$ & $\begin{array}{l}\text { User exposed to } 2 \\
\text { different levels from forest } \\
\text { to cave with snakes }\end{array}$ & 2 levels & \\
\hline$[32]$ & Height Phobia & $\operatorname{VRET}(n=10)$ & $21-25$ & $\begin{array}{l}\text { Users exposed to } 3 \\
\text { different stages (river, city, } \\
\text { and mountain) }\end{array}$ & 3 stages & \\
\hline [33] & Shark Phobia & $\operatorname{VRET}(n=1)$ & 30 & $\begin{array}{l}\text { Three stages navigated by } \\
\text { the user, pool then lake } \\
\text { finally the sea, the user } \\
\text { can walk and swim freely }\end{array}$ & 3 stages & \\
\hline [34] & Height Phobia & $\operatorname{VRET}(n=20)$ & $20-21$ & $\begin{array}{l}\text { Two levels used one for } \\
\text { the mountain and the } \\
\text { other is the city }\end{array}$ & $\begin{array}{l}2 \text { levels to } \\
8 \text { sessions }\end{array}$ & $25 \mathrm{~min}$ \\
\hline [35] & $\begin{array}{l}\text { Cockroach } \\
\text { Phobia }\end{array}$ & $\begin{array}{l}\text { AR Mobile app } \\
\qquad(n=13)\end{array}$ & $20-23$ & $\begin{array}{l}\text { Four different scenarios } \\
\text { displayed to the patients } \\
\text { include single static } \\
\text { cockroach, single dynamic } \\
\text { cockroach, multiple static } \\
\text { cockroaches, and multiple } \\
\text { dynamic cockroaches }\end{array}$ & $\begin{array}{c}4 \\
\text { scenarios }\end{array}$ & \\
\hline [36] & Spider Phobia & AR Mobile app $(n=16)$ & $18-20$ & $\begin{array}{c}\text { Four stages determined } \\
\text { based on the patient fear } \\
\text { level }\end{array}$ & 3 levels & $60 \mathrm{~min}$ \\
\hline [14] & Dental Phobia & $\operatorname{VRET}(n=2)$ & 24 and 56 & $\begin{array}{l}\text { The patient was exposed } \\
\text { to five scenarios including } \\
\text { seating with no dental } \\
\text { tools, mouth mirror, and } \\
\text { oral cavity, injection, } \\
\text { using the muted drill, and } \\
\text { using a drill with sound }\end{array}$ & 2 sessions & $45 \mathrm{~min}$ \\
\hline [37] & Height Phobia & $\begin{array}{l}\text { 1: e-VRET }(n=6) \\
\text { 2: p-VRET }(n=6)\end{array}$ & $18-65$ & $\begin{array}{l}\text { Two virtual worlds } \\
\text { subway station and } \\
\text { 24-storey tower block }\end{array}$ & 6 sessions & \\
\hline [19] & Dental Phobia & $\begin{array}{c}\text { 1: VRET }(n=15) \\
\text { 2: Psychoeducation with } \\
\text { information pamphlet }(n=15)\end{array}$ & $18-50$ & $\begin{array}{l}\text { Five scenarios contain } \\
\text { seating with no dental } \\
\text { tools, mouth mirror, and } \\
\text { oral cavity, injection, } \\
\text { using the muted drill, and } \\
\text { using a drill with sound }\end{array}$ & 1 session & $40 \mathrm{~min}$ \\
\hline [39] & Spider Phobia & $\begin{array}{l}\text { 1: } \operatorname{VRET}(n=50) \\
2: \operatorname{IVET}(n=50)\end{array}$ & $\geq 18$ & $\begin{array}{c}\text { VRET contains } 8 \text { levels of } \\
\text { increasingly realistic } \\
\text { spider } \\
\text { IVET with } 3 \text { different size } \\
\text { spiders }\end{array}$ & 1 session & $180 \mathrm{~min}$ \\
\hline
\end{tabular}


Table 5. Cont.

\begin{tabular}{|c|c|c|c|c|c|c|}
\hline Paper & Phobia Type & $\begin{array}{l}\text { Treatment Condition and } \\
\text { Sample Size }\end{array}$ & Age Range & Solution & Session Number & $\begin{array}{l}\text { Session } \\
\text { Length }\end{array}$ \\
\hline [40] & $\begin{array}{l}\text { Blood-Injection- } \\
\text { Injury (BII) } \\
\text { Phobia }\end{array}$ & $\begin{array}{l}\text { 1: } \operatorname{VRET}(n=21) \\
2: \operatorname{IVET}(n=22)\end{array}$ & $\geq 18$ & $\begin{array}{l}\text { Patient exposed to two } \\
360 \text { videos of a nurse } \\
\text { taking a blood sample and } \\
\text { giving an injection }\end{array}$ & 2 sessions & $\begin{array}{l}\text { VRET } 90 \mathrm{~min} \\
\text { WL } 30 \mathrm{~min}\end{array}$ \\
\hline [41] & $\begin{array}{l}\text { Spider/Cockroach } \\
\text { Phobia }\end{array}$ & $\begin{array}{c}\text { 1: } \operatorname{AR}(n=32) \\
\text { 2: } \operatorname{IVET}(n=31)\end{array}$ & $20-70$ & $\begin{array}{l}\text { Participants exposed to a } \\
\text { 3D spider or cockroaches }\end{array}$ & 1 session & $180 \mathrm{~m}$ \\
\hline [42] & Driving Phobia & VRET $(n=14)$ & $28-53$ & $\begin{array}{l}\text { Each session contains } 4 \\
\text { scenarios that start with } \\
\text { the least anxiety level }\end{array}$ & 5 sessions & 5 to $60 \mathrm{~min}$ \\
\hline [21] & Height Phobia & $\begin{array}{l}\text { 1: } \operatorname{VRET}(n=95) \\
2: \operatorname{WL}(n=95)\end{array}$ & $18-65$ & $\begin{array}{l}\text { A self-guided game that } \\
\text { asks the user to complete } \\
\text { several assignments and } \\
\text { view four } 360 \text { videos }\end{array}$ & 6 modules & $\begin{array}{l}5 \text { to } 20 \text { min } \\
\text { for each } \\
\text { module }\end{array}$ \\
\hline [43] & Spider Phobia & $\begin{array}{l}\text { 1: } \operatorname{VRET}(n=38) \\
\text { 2: psychoeducation only } \\
\text { control group }(n=39)\end{array}$ & $18-65$ & $\begin{array}{l}\text { Exposed to } 360 \text { immersive } \\
\text { videos that last } 5 \text { min for } \\
\text { each video for } 6 \text { times } \\
\text { using Oculus Rift virtual } \\
\text { reality headset the } \\
\text { intensity increased with } \\
\text { time where the spider } \\
\text { moving closer or moving } \\
\text { towards the camera }\end{array}$ & 6 sessions & $30 \mathrm{~min}$ \\
\hline [46] & Height Phobia & $\operatorname{VRET}(n=20)$ & $20-30$ & $\begin{array}{l}\text { The session starts with the } \\
\text { user finding himself on a } \\
\text { high floor inside an } \\
\text { apartment room and must } \\
\text { accomplish several tasks } \\
\text { including getting out of } \\
\text { the balcony open door, } \\
\text { then they must hold onto } \\
\text { the balcony the railing for } \\
\text { minutes, and finally get } \\
\text { the hanging object in front } \\
\text { of him }\end{array}$ & 1 session & $45 \mathrm{~min}$ \\
\hline [44] & Height Phobia & $\begin{array}{l}\text { 1: } \operatorname{VRET}(n=49) \\
\text { 2: } \operatorname{TAU}(n=51)\end{array}$ & $30-58$ & $\begin{array}{l}\text { Patients find themselves } \\
\text { in a building consisting of } \\
10 \text { floors and the couch } \\
\text { guides the user through } \\
\text { the process and provides } \\
\text { them with the full } \\
\text { description of each task. } \\
\text { Moreover, the user can } \\
\text { choose one of the first } 5 \\
\text { floors to achieve certain } \\
\text { activities, but each floor } \\
\text { has a certain activity, } \\
\text { ranging from easier tasks } \\
\text { to harder ones }\end{array}$ & 6 sessions & $30 \mathrm{~min}$ \\
\hline [45] & Flight Phobia & VRET & $20-65$ & $\begin{array}{l}\text { The patient was exposed } \\
\text { to three different virtual } \\
\text { flights }\end{array}$ & 3 sessions & $75 \mathrm{~min}$ \\
\hline
\end{tabular}

\section{Discussion}

This paper reviews current literature on the topic of VRET and ARET and answer several questions regarding the usability of the treatments. It investigates the previous studies that used either VR and/or AR to treat any type of specific phobia in the last five years. It also provides some additional research direction for improving the case for mainstreaming VRET and/or ARET.

The main finding of this systematic review is focusing on the feasibility of using virtual reality or augmented reality as an exposure therapy to treat different types of specific phobia. 
Virtual reality has proved its ability to treat various types of a specific phobia including animal phobia, natural phobia, situational phobia, and blood-injection-injury phobia. On the other hand, augmented reality has proved its efficiency in only one type of specific phobia: animal phobia. Figure 4 shows the types of specific phobias discussed in this review. Figure 5 shows that AR and VR vary in treatment.

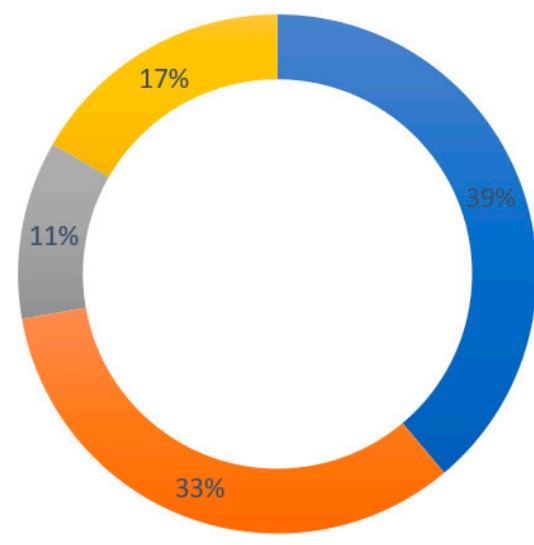

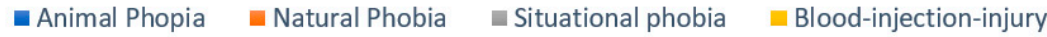

Figure 4. Types of specific phobias.

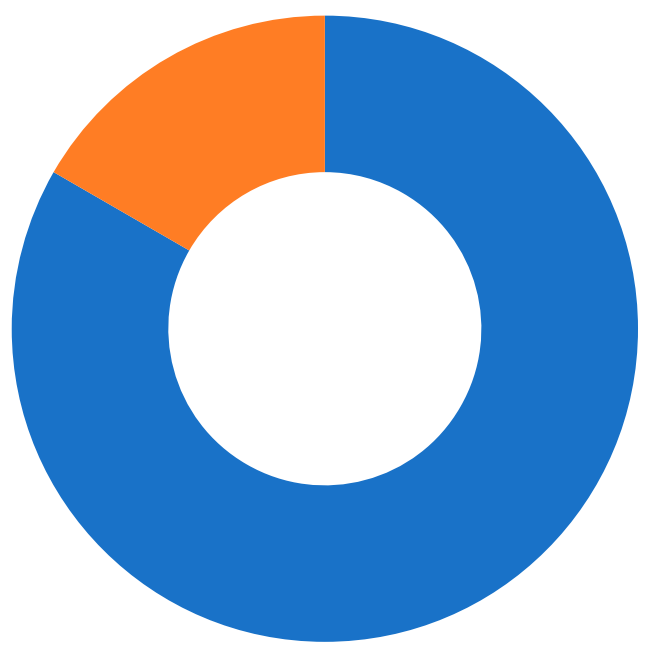

- Virtual reality $\quad$ Augmanted reality

Figure 5. Dominant technology in treating specific phobias.

In virtual reality, we found that 15 studies in total proved the efficiency of using virtual reality in exposure therapy. Eight of the studies have not compared virtual reality exposure therapy to any other treatment methods [32]. Moreover, the other studies compare it to a different type of trial including in vivo treatment [39-41], remote therapy without the presence of the therapist [37], psychoeducation with an information pamphlet [38], and waitlist [21], which were all used to support the effectiveness of the virtual reality exposure therapy. Different types of specific phobias treated using virtual reality include animal phobias with various types of animals such as spiders [43], sharks [33], and snakes [24]. Moreover, there are situational phobias such as driving phobia [42] and flight phobia [45], natural phobias such as a height phobia [32], and blood-injection-injury phobia [40], which also includes dental phobias [14]. 
Furthermore, due to the significant degree of control that this technology provides, many experimental investigations have proved the utility of VR in testing theories linked to the processes and mechanisms involved in exposure therapy. Similarly, multiple research studies have demonstrated that virtual reality (VR) is an effective tool for studying critical elements associated to fear activation/reduction in the lab, as well as for generating helpful ideas for establishing novel treatment strategies to improve therapeutic outcomes.

In augmented reality, there are only three studies that prove the potential and effectiveness of using augmented reality in exposure therapy to treat different types of specific phobias. One of the studies compares its effectiveness to in vivo exposure therapy [41], while the other two have not compared it to any treatment $[35,36]$. However, these types include spider phobias [36] cockroach phobias [35] and both spider and cockroach phobias [41], which all are part of animal phobias. Moreover, one of the studies is a randomized controlled trial [41], while the other is a case study [35]. We noticed that augmented reality has been tested on only one type of specific phobia, animal phobia, which proves its ability for treatment efficiently.

We would like to highlight the fact that most studies included information about the follow-up process after VR/AR exposure therapy sessions. For instance, ref. [49] discuss the short- and long-term efficacy of virtual reality (VR) exposure therapy for the treatment of flying phobia (FP). They present data from pre-treatment, post-treatment, and 1-year follow-up assessments in a sample of nine participants using a multiple baseline design. The results obtained at post-treatment and 1 year after the completion of the treatment support the efficacy of VR in the treatment of flying phobia. Moreover, several studies with larger samples report evidence of the maintenance of treatment for a long-term period [50].

Overall, the studies included were mostly randomized controlled trials that were tested on adults more than 18 years old from both genders that must have the tested phobia. In addition, the treatment sessions' numbers vary based on the increased difficulty and realism of the 3D models used. Additionally, a number of the studies did a follow-up to check the treatment efficiency.

VRET / ARET applications have evolved into a viable alternative that, in terms of efficacy, can meet the results of traditional phobia treatments. They are, nevertheless, tools that can be used to improve the field of psychiatric treatment. There will be a major increase in the routine usage of these VRET/ARET applications in clinical settings in the future years, but there are significant difficulties to overcome first. The acceptability of these technologies by clinicians is the most significant factor. This acceptability will be linked to further cost savings, the development of simple-to-use devices, and the deployment of initiatives and programs to train clinicians. Virtual reality applications can be quite beneficial in the treatment of phobias.

\section{Conclusions}

Through a systematic approach, this study aims to present the state of the art of VRET and ARET as a useful way to treat phobias. More applications and experiments in this field exist, and this effort tries to address some research questions in order to provide useful findings for future research and to complement previous ARET/VRET review studies. Without claiming to offer an exhaustive study, this paper seeks to systematize research papers related to phobia exposure therapy and to present the general characteristics of VR/AR-based systems developed for this field, as well as the existing benefits and challenges. As for results, 18 papers have developed an exposure therapy that was found to be efficient in treating the phobia types: animal phobias, natural phobias, situational phobias, and blood-injection-injury phobias. VRET applications are emerging as an effective alternative that can rival the results of traditional treatments for phobias in terms of efficacy. Routine use of these VRET applications in clinical situations will increase significantly over the next few years, but there are important challenges to overcome first. Users' acceptance of these techniques is very important. This acceptance involves additional cost savings, the development of easy-to-use devices, and the implementation of programs and actions 
to train clinic staff. To move forward in this area, new research lines need to find the best strategies to improve exposure therapy, reduce the recurrence of anxiety, and increase acceptance of exposure-based treatments.

On the other hand, this study identifies a research gap in the efficacy of ARET in the treatment of particular phobia. This could be due to the fact that ARET research is still in its early stages, and most studies to date have concentrated on other disorders. ARET, for example, has been shown to be effective for patients with post-traumatic stress disorder (PTSD) [51] or anxiety disorders [52].

We believe that ARET has the potential to be a successful treatment for PTSD and that it may be preferable to VRET in some cases. ARET differs from VRET in that it allows the patient to place augmented things in his or her actual environment. In addition, instead of the computerized body that is commonly utilized in VRET, ARET allows patients to see their own bodies. This could lead to higher degrees of presence. Furthermore, when employing ARET, the patient's actual surroundings are augmented, but the VRET environment must be entirely developed.

However, some methodological issues should be taken into consideration. Our SLR comprehensively summarizes the empirical studies using only 18 research articles based on a search strategy by examining several databases, including PubMed, ProQuest, Scopus, Web of Science, and Google Scholar. Consequently, certain related studies may not be included as the search was performed considering journal papers published over five years (2016-2020). Moreover, non-English studies were excluded. In addition, some database searches are not included. The selected studies were conducted in a controlled research context, which makes it difficult to detect the degree of the feasibility of VRET/ARET in natural clinical settings. Thus, it is necessary to carry out effectiveness and cost-effectiveness studies in different delivery contexts (hospitals, private practices).

Author Contributions: Conceptualization, G.A., R.B. and S.K.; methodology, G.A., R.B. and W.A.; software, G.A. and R.B.; validation, G.A., R.B., W.A. and S.K.; formal analysis, G.A., M.A.-S. and F.S.; investigation, R.B. and S.K.; resources, R.B. and W.A.; data curation, F.S. and M.H.; writing-original draft preparation, G.A., R.B. and W.A.; writing-review and editing, S.K., F.S. and M.H.; visualization, M.H. and M.A.-S.; supervision, R.B. and S.K.; project administration, R.B.; funding acquisition, F.S. and M.H. All authors have read and agreed to the published version of the manuscript.

Funding: This research received no external funding.

Institutional Review Board Statement: Not applicable.

Informed Consent Statement: Not applicable.

Data Availability Statement: Not applicable.

Acknowledgments: The researchers would like to thank the Deanship of Scientific Research, Qassim University for funding the publication of this project.

Conflicts of Interest: The authors declare no conflict of interest.

\section{References}

1. Botella, C.; Fernández-Álvarez, J.; Guillén, V.; García-Palacios, A.; Baños, R. Recent Progress in Virtual Reality Exposure Therapy for Phobias: A Systematic Review. Curr. Psychiatry Rep. 2017, 19. [CrossRef]

2. Carl, E.; Stein, A.T.; Levihn-Coon, A.; Pogue, J.R.; Rothbaum, B.; Emmelkamp, P.; Asmundson, G.J.; Carlbring, P.; Powers, M.B. Virtual reality exposure therapy for anxiety and related disorders: A meta-analysis of randomized controlled trials. J. Anxiety Disord. 2019, 61, 27-36. [CrossRef] [PubMed]

3. Papagiannis, H. Augmented Human How Technology Is Shaping the New Reality; O'Reilly Media: Sebastopol, CA, USA, 2018.

4. Tsai, C.F.; Yeh, S.C.; Huang, Y.; Wu, Z.; Cui, J.; Zheng, L. The Effect of Augmented Reality and Virtual Reality on Inducing Anxiety for Exposure Therapy: A Comparison Using Heart Rate Variability. J. Healthc. Eng. 2018, 2018, 6357351. [CrossRef] [PubMed]

5. Thng, C.E.W.; Lim-Ashworth, N.S.J.; Poh, B.Z.Q.; Lim, C.G. Recent developments in the intervention of specific phobia among adults: A rapid review. F1000Research 2020, 9, 195. [CrossRef]

6. Oing, T.; Prescott, J. Implementations of Virtual Reality for Anxiety-Related Disorders: Systematic Review. J. Med. Internet Res. 2018, 20, 10965. [CrossRef] 
7. Ahmed, S. Frontotemporal dementia treatment: A review. Int. J. Basic Clin. Pharmacol. 2016, 5, 1179-1180. [CrossRef]

8. Hoffman, H.G.; Garcia-Palacios, A.; Carlin, A.; Furness, T.A., III; Botella-Arbona, C. Interfaces That Heal: Coupling Real and Virtual Objects to Treat Spider Phobia. Int. J. Hum.-Comput. Interact. 2003, 16, 283-300. [CrossRef]

9. Banos, R.M.; Botella, C.; Perpina, C.; Alcaniz, M.; Lozano, J.A.; Osma, J.; Gallardo, M. Virtual reality treatment of flying phobia. IEEE Trans. Inf. Technol. Biomed. 2002, 6, 206-212. [CrossRef]

10. Wald, J.; Taylor, S. Efficacy of virtual reality exposure therapy to treat driving phobia: A case report. J. Behav. Ther. Exp. Psychiatry 2000, 31, 249-257. [CrossRef]

11. North, M.M.; North, S.M.; Coble, J.R. Effectiveness of Virtual Environment Desensitization in the Treatment of Agoraphobia. Presence Teleoper. Virtual Environ. 1996, 5, 346-352. [CrossRef]

12. Mason, E.C.; Gaston, J.E.; Pestell, C.F.; Page, A.C. A comprehensive group-based cognitive behavioural treatment for bloodinjection-injury phobia. Br. J. Clin. Psychol. 2021; online first. [CrossRef]

13. Meindl, J.N.; Saba, S.; Gray, M.; Stuebing, L.; Jarvis, A. Reducing blood draw phobia in an adult with autism spectrum disorder using low-cost virtual reality exposure therapy. J. Appl. Res. Intellect. Disabil. 2019, 32, 1446-1452. [CrossRef] [PubMed]

14. Gujjar, K.R.; Sharma, R.; De Jongh, A. Virtual reality exposure therapy for treatment of dental phobia. Dent. Update 2017, 44, 423-435. [CrossRef] [PubMed]

15. Wolitzky-Taylor, K.B.; Horowitz, J.D.; Powers, M.B.; Telch, M.J. Psychological approaches in the treatment of specific phobias: A meta-analysis. Clin. Psychol. Rev. 2008, 28, 1021-1037. [CrossRef]

16. Freitas, J.R.S.; Velosa, V.H.S.; Abreu, L.T.N.; Jardim, R.L.; Santos, J.A.V.; Peres, B.; Campos, P.F. Virtual Reality Exposure Treatment in Phobias: A Systematic Review. Psychiatr. Q. 2021, 92, 1685-1710. [CrossRef] [PubMed]

17. Ollendick, T.H.; Davis, T.E. One-Session Treatment for Specific Phobias: A Review of Öst's Single-Session Exposure with Children and Adolescents. Cogn. Behav. Ther. 2013, 42, 275-283. [CrossRef] [PubMed]

18. Koch, E.I.; Spates, C.R.; Himle, J.A. Comparison of behavioral and cognitive-behavioral one-session exposure treatments for small animal phobias. Behav. Res. Ther. 2004, 42, 1483-1504. [CrossRef]

19. Böhnlein, J.; Altegoer, L.; Muck, N.K.; Roesmann, K.; Redlich, R.; Dannlowski, U.; Leehr, E.J. Factors influencing the success of exposure therapy for specific phobia: A systematic review. Neurosci. Biobehav. Rev. 2020, 108, 796-820. [CrossRef]

20. Craske, M.G.; Treanor, M.; Conway, C.C.; Zbozinek, T.; Vervliet, B. Maximizing exposure therapy: An inhibitory learning approach. Behav. Res. Ther. 2014, 58, 10-23. [CrossRef]

21. Donker, T.; Van Esveld, S.; Fischer, N.; Van Straten, A. OPhobia-towards a virtual cure for acrophobia: Study protocol for a randomized controlled trial. Trials 2018, 19, 433. [CrossRef]

22. Maples-Keller, J.L.; Yasinski, C.; Manjin, N.; Rothbaum, B.O. Virtual Reality-Enhanced Extinction of Phobias and Post-Traumatic Stress. Neurotherapeutics 2017, 14, 554-563. [CrossRef]

23. Klumpner, C.; Wijekoon, T.; Wheeler, P. New methods for the active compensation of unbalanced supply voltages for two-stage direct power converters. IEEJ Trans. Ind. Appl. 2006, 126, 589-598. [CrossRef]

24. Toma, E.; Balan, O.; Lambru, C.; Moldoveanu, A.; Moldoveanu, F. Ophiophobia 3D-A Game for Treating Fear of Snakes. In Proceedings of the 2020 IEEE 10th International Conference on Intelligent Systems, IS 2020, Varna, Bulgaria, 28-30 August 2020; IEEE: New York, NY, USA, 2020.

25. Norton, P.J.; Price, E.C. A Meta-Analytic Review of Adult Cognitive-Behavioral Treatment Outcome across the Anxiety Disorders. J. Nerv. Ment. Dis. 2007, 195, 521-531. [CrossRef] [PubMed]

26. Parisi, T. Learning Virtual Reality: Developing Immersive Experiences and Applications, 1st ed.; O'Reilly Media: Newton, MA, USA, 1 December 2015.

27. Klinger, E.; Bouchard, S.; Légeron, P.; Roy, S.; Lauer, F.; Chemin, I.; Nugues, P. Virtual Reality Therapy Versus Cognitive Behavior Therapy for Social Phobia: A Preliminary Controlled Study. CyberPsychol. Behav. 2005, 8, 76-88. [CrossRef]

28. Sherman, W.R.; Craig, A.B. Understanding Virtual Reality: Interface, Application, and Design. Presence Teleoper. Virtual Environ. 2003, 12, 441-442. [CrossRef]

29. Hugues, O.; Fuchs, P.; Nannipieri, O. New Augmented Reality Taxonomy: Technologies and Features of Augmented Environment. In Handbook of Augmented Reality; Springer: New York, NY, USA, 2011; pp. 47-63. [CrossRef]

30. Pot-Kolder, R.; Veling, W.; Counotte, J.; van der Gaag, M. Anxiety Partially Mediates Cybersickness Symptoms in Immersive Virtual Reality Environments. Cyberpsychol. Behav. Soc. Netw. 2018, 21, 187-193. [CrossRef]

31. Krzystanek, M.; Surma, S.; Stokrocka, M.; Romańczyk, M.; Przybyło, J.; Krzystanek, N.; Borkowski, M. Tips for Effective Implementation of Virtual Reality Exposure Therapy in Phobias-A Systematic Review. Front. Psychiatry 2021, $12,737351$. [CrossRef]

32. Suyanto, E.M.; Angkasa, D.; Turaga, H.; Sutoyo, R. Overcome Acrophobia with the Help of Virtual Reality and Kinect Technology. Procedia Comput. Sci. 2017, 116, 476-483. [CrossRef]

33. Malbos, E.; Burgess, G.H.; Lançon, C. Virtual Reality and Fear of Shark Attack: A Case Study for the Treatment of Squalophobia. Clin. Case Stud. 2020, 19, 339-354. [CrossRef]

34. Abdullah, M.; Shaikh, Z.A. An effective virtual reality based Remedy for acrophobia. Int. J. Adv. Comput. Sci. Appl. 2018, 9, 162-167. [CrossRef] 
35. Fatharany, F.; Hariadi, R.R.; Herumurti, D.; Yuniarti, A. Augmented reality application for cockroach phobia therapy using everyday objects as marker substitute. In Proceedings of the 2016 International Conference on Information and Communication Technology and Systems, Surabaya, Indonesia, 12 October 2016; IEEE: New York, NY, USA.

36. Plasencia, A.R.G.; Escobar-Sánchez, M.E. Interactive multiplatform software to mitigate arachnophobia through augmented reality. KnE Eng. 2018, 1, 108. [CrossRef]

37. Levy, F.; Leboucher, P.; Rautureau, G.; Jouvent, R. E-virtual reality exposure therapy in acrophobia: A pilot study. J. Telemed. Telecare 2016, 22, 215-220. [CrossRef]

38. Gujjar, K.R.; van Wijk, A.; Kumar, R.; de Jongh, A. Efficacy of virtual reality exposure therapy for the treatment of dental phobia in adults: A randomized controlled trial. J. Anxiety Disord. 2019, 62, 100-108. [CrossRef]

39. Miloff, A.; Lindner, P.; Dafgård, P.; Deak, S.; Garke, M.; Hamilton, W.; Heinsoo, J.; Kristoffersson, G.; Rafi, J.; Sindemark, K. Automated virtual reality exposure therapy for spider phobia vs. in-vivo one-session treatment: A randomized non-inferiority trial. Behav. Res. Ther. 2019, 118, 130-140. [CrossRef]

40. Jiang, M.Y.W.; Upton, E.; Newby, J.M. A randomised wait-list controlled pilot trial of one-session virtual reality exposure therapy for blood-injection-injury phobias. J. Affect. Disord. 2020, 276, 636-645. [CrossRef]

41. Botella, C.; Pérez-Ara, M.Á.; Bretón-López, J.; Quero, S.; García-Palacios, A.; Baños, R.M. In Vivo versus augmented reality exposure in the treatment of small animal phobia: A randomized controlled trial. PLoS ONE 2016, 11, e0148237. [CrossRef] [PubMed]

42. Kaussner, Y.; Kuraszkiewicz, A.M.; Schoch, S.; Markel, P.; Hoffmann, S.; Baur-Streubel, R.; Kenntner-Mabiala, R.; Pauli, P. Treating patients with driving phobia by virtual reality exposure therapy-A pilot study. PLoS ONE 2020, 15, e0226937. [CrossRef] [PubMed]

43. Minns, S.; Levihn-Coon, A.; Carl, E.; Smits, J.A.; Miller, W.; Howard, D.; Papini, S.; Quiroz, S.; Lee-Furman, E.; Telch, M.; et al. Immersive 3D exposure-based treatment for spider fear: A randomized controlled trial. J. Anxiety Disord. 2019, 61, 37-44. [CrossRef]

44. Freeman, D.; Haselton, P.; Freeman, J.; Spanlang, B.; Kishore, S.; Albery, E.; Denne, M.; Brown, P.; Slater, M.; Nickless, A. Automated psychological therapy using immersive virtual reality for treatment of fear of heights: A single-blind, parallel-group, randomised controlled trial. Lancet Psychiatry 2018, 5, 625-632. [CrossRef]

45. Shiban, Y.; Diemer, J.; Müller, J.; Brütting-schick, J.; Pauli, P.; Mühlberger, A. Diaphragmatic breathing during virtual reality exposure therapy for aviophobia: Functional coping strategy or avoidance behavior ? A pilot study. BMC Psychiatry 2017, 17, 29. [CrossRef]

46. Kritikos, J.; Zoitaki, C.; Tzannetos, G.; Mehmeti, A.; Douloudi, M.; Nikolaou, G.; Alevizopoulos, G.; Koutsouris, D. Comparison between Full Body Motion Recognition Camera Interaction and Hand Controllers Interaction used in Virtual Reality Exposure Therapy for Acrophobia. Sensors 2020, 20, 1244. [CrossRef]

47. Szymanski, J.; O’Donohue, W. Fear of Spiders Questionnaire. J. Behav. Ther. Exp. Psychiatry 1995, 26, 31-34. [CrossRef]

48. Oar, E.L.; Farrell, L.J.; Ollendick, T.H. One Session Treatment for Specific Phobias: An Adaptation for Paediatric Blood-InjectionInjury Phobia in Youth. Clin. Child. Fam. Psychol. Rev. 2015, 18, 370-394. [CrossRef] [PubMed]

49. Botella, C.; Osma, J.; Garcia-Palacios, A.; Quero, S.; Baños, R.M. Treatment of flying phobia using virtual reality: Data from a 1-year follow-up using a multiple baseline design. Clin. Psychol. Psychother. 2004, 11, 311-323. [CrossRef]

50. Rothbaum, B.O.; Hodges, L.; Anderson, P.L.; Price, L.; Smith, S. Twelve-month follow-up of virtual reality and standard exposure therapies for the fear of flying. J. Consult. Clin. Psychol. 2002, 70, 428-432. [CrossRef] [PubMed]

51. Eshuis, L.V.; van Gelderen, M.J.; van Zuiden, M.; Nijdam, M.J.; Vermetten, E.; Olff, M.; Bakker, A. Efficacy of immersive PTSD treatments: A systematic review of virtual and augmented reality exposure therapy and a meta-analysis of virtual reality exposure therapy. J. Psychiatr. Res. 2021, 143, 516-527. [CrossRef] [PubMed]

52. Chicchi Giglioli, I.A.; Pallavicini, F.; Pedroli, E.; Serino, S.; Riva, G. Augmented Reality: A Brand New Challenge for the Assessment and Treatment of Psychological Disorders. Comput. Math. Methods Med. 2015, 2015, 862942. [CrossRef] [PubMed] 